\title{
Brainstem reflexes and brainstem auditory evoked responses in Huntington's chorea
}

\author{
E BOLLEN,* RJHM ARTS, $\dagger$ RAC ROOS,* EA VAN DER VELDE, $\ddagger$ OJS BURUMA* \\ From the Departments of Neurology* and Clinical Neurophysiology, $\uparrow$ Academic Hospital, Leiden, and \\ Department of Medical Statistics, $\ddagger$ State University Leiden, Leiden, The Netherlands
}

SUMMARY Blink reflex, corneal reflex, jaw reflex, exteroceptive suppression in masseter muscles and brainstem auditory evoked potentials were measured in 20 patients with Huntington's chorea and 12 controls. A significantly increased latency of the second component of the homolateral and heterolateral blink reflex was found in the patient group as compared with the controls. The other investigations revealed no significant differences between patients and controls except for some facilitation of the jaw reflex in the patient group. Increase of second component latency of the blink reflex in the presence of normal corneal reflexes is suggestive of functional impulse conduction disturbance in the lower brainstem. It is discussed whether in Huntington's chorea this is to be attributed to alterations of cortical or striatal influence or to local brainstem abnormalities.

The morphological and functional extent of damage of the central nervous system in Huntington's chorea has still to be determined. This particularly pertains to the lower brainstem. Histological investigations have revealed various changes in the olives, the vestibular, vagal and hypoglossal nuclei. ${ }^{1}$ Also functional abnormalities attributable to brainstem lesions have been found in patients with Huntington's chorea, for instance in oculomotor studies ${ }^{2}$ and in blink reflex investigations. ${ }^{34}$ Nothing unequivocally abnormal has been noted in brainstem auditory evoked responses. ${ }^{5}$ In studies of somatosensory evoked potentials, conflicting results have been reported concerning the central brain conduction time, which is an indicator of lower as well as of higher brainstem derangement. ${ }^{5}$ To the best of our knowledge, electrophysiological measurements of the jaw reflex, the exteroceptive suppression of activity in masseter muscles and the corneal reflex have not been reported in Huntington's chorea. Accordingly, it seemed worthwhile to study the brainstem reflexes as well as to reexamine the blink reflex and the brainstem auditory evoked respunses so as to try to determine the extent of brainstem integrity in Huntington's chorea.

Address for reprint requests: E Bollen, Department of Neurology, Academic Hospital, Leiden, Rijnsburgerweg 10, 2333 AA Leiden, The Netherlands.

Received 12 February 1985 and in revised form 16 July 1985. Accepted 23 July 1985.

\section{Patients}

After informed consent was obtained, according to the Declaration of Helsinki of 1975 , twenty patients with Huntington's chorea were studied (10 males, 10 females). Age ranged from 29 to 54 years, (mean: $47 \cdot 1$ years). The duration of illness varied between 1 and 9 years (mean: $4 \cdot 1$ years). All patients showed characteristic choreic movements and had a positive family history for Huntington's chorea. Five patients showed moderate to severe cognitive impairment. The patients showed neither signs nor symptoms indicative for other neurological diseases. Fourteen patients were taking drugs. Medication had not been changed in the 3 months prior to the study. Four patients were taking dopamine-antagonists (tetrabenazine, tiapride, haloperidol or thiopropazate). Two patients took benzodiazepines (diazepam or chlordiazepoxide) and two patients tricyclic antidepressants (amitriptyline or imipramine). The spouses, if available, were used as controls ( 12 controls, 6 males, 6 females, mean age: $48 \cdot 8$ years, age range 26 to 51 years). The controls showed neither signs nor symptoms of neurological disease and were not on any kind of medication.

\section{Methods}

The methods used for recording reflexes running along the trigeminal system have been described by Ongerboer de Visser et al. ${ }^{6-8}$ Surface electrodes were connected with a Medelec MS 6 electromyograph. Stimuli were delivered through the Medelec surface stimulator. Latencies of blink reflex, corneal reflex and jaw reflex were defined as the mean of at least three measurements. Duration of the exteroceptive suppression of activity in masseter muscles was 
Table Mean values and standard deviation of blink reflex, jaw reflex and corneal reflex in 20 patients with Huntington's chorea and 12 controls

\begin{tabular}{|c|c|c|c|c|}
\hline & & $\begin{array}{l}\text { Huntington's chorea } \\
\text { mean SD }\end{array}$ & $\begin{array}{l}\text { Controls } \\
\text { mean } S D\end{array}$ & $p$ \\
\hline $\begin{array}{l}\text { BR latency (ms) } \\
\text { Stimulation on right side } \\
\text { BR latency (ms) } \\
\text { Stimulation on left side } \\
\text { JR latency (ms) } \\
\text { CR latency (ms) } \\
\text { Stimulation on right side } \\
\text { CR latency (ms) } \\
\text { Stimulation on left side }\end{array}$ & $\begin{array}{l}\text { R1 } \\
\text { R2 right } \\
\text { R2 left } \\
\text { R1 } \\
\text { R2 right } \\
\text { R2 left } \\
\text { Right side } \\
\text { Left side } \\
\text { R right } \\
\text { R left } \\
\text { R right } \\
\text { R left }\end{array}$ & $\begin{array}{l}10.7 \pm 2.4 \\
41.6 \pm 10.8 \\
44.6 \pm 16.2 \\
10.9 \pm 2.8 \\
40.5 \pm 9.4 \\
38.5 \pm 9.0 \\
5.9 \pm 3.2 \\
6.0 \pm 3.3 \\
43.7 \pm 22.8 \\
47.8 \pm 23.6 \\
51.5 \pm 22.6 \\
46.3 \pm 20.4\end{array}$ & $\begin{array}{r}10.6 \pm 1.8 \\
36.2 \pm 11.4 \\
36.1 \pm 9.8 \\
11.0 \pm 2.6 \\
34.7 \pm 7.8 \\
33.5 \pm 8.6 \\
7.0 \pm 1.0 \\
6.8 \pm 1.9 \\
41.2 \pm 15.2 \\
44.7 \pm 16.4 \\
46.6 \pm 24.0 \\
43.2 \pm 22.2\end{array}$ & $\begin{array}{l}\text { NS } \\
0.001 \\
0.001 \\
\text { NS } \\
0.003 \\
0.001 \\
0.02 \\
\text { NS }(0.07) \\
\text { NS } \\
\text { NS } \\
\text { NS } \\
\text { NS }\end{array}$ \\
\hline
\end{tabular}

The $p$ values pertain to Wilcoxon's two sample test. NS: no significant differences. BR: blink reflex. CR: corneal reflex. JR: jaw reflex.

defined as the mean of at least three periods free of continuous electromyographic activity. To prevent habituation effects on the blink reflex one per 60 second stimuli were delivered to the supra-orbital nerves.

Auditory evoked potentials were obtained by delivering rarefaction clicks (duration $0.1 \mathrm{~ms}$, rate $16.3 \mathrm{~Hz}$, intensity 70 $\mathrm{dB}$ ) at one ear, masking the contralateral ear by a $30 \mathrm{~dB}$ lower level white noise. Recordings were taken from homoand heterolateral mastoid bone, reference to the vertex $(\mathrm{Cz}$ region, international 10-20 system) over a period of $12 \mathrm{~ms}$ (including a $10 \%$ prestimulus interval). Sampling rate was $42 \mathrm{KHz}$. Averaging was performed employing an automatic artefact rejection circuit at a $95 \%$ amplifier sensitivity level $(50 \mu \mathrm{V})$. Amplifier bandpass was 150-3000 Hz. Positive peaks were labelled (positive meaning positivity at the vertex relative to the mastoid electrode) according to the Jewett nomenclature. ${ }^{9}$ The apparatus used was a Nicolet Pathfinder II. The persons studied were kept alert by verbal contact during the whole procedure.

Statistical evaluation was performed according to the Wilcoxon's two sample test.

\section{Results}

The latency of the homo- and heterolateral second response of the blink reflex on stimulation of either side was significantly prolonged (table) when compared with the controls. The right jaw reflex latency was significantly shorter in the patients than in the controls (table). The latencies of the corneal reflex on either side were longer in the patients than in the controls. However, differences in corneal reflex latencies were not statistically significant (table). The duration of the exteroceptive suppression of activity in masseter muscles and the amplitudes and latencies of the brainstem auditory evoked responses did not differ significantly between patients and controls (results not shown).

\section{Discussion}

In this study no statistically significant differences were found between patients and controls with respect to the exteroceptive suppression of activity in masseter muscles and the corneal reflex.

In the only report so far on auditory responses wits latencies less than $8 \mathrm{~ms}$ in Huntington's chores normal latencies and amplitudes were reported in 1 웅 patients. ${ }^{5}$ Our results confirm these latter findings in larger patient group.

A tendency to latency decrease of the jaw reflex was noticed in the patients as compared with controls reaching a statistically significant level on the righ $\overline{\bar{p}}$. side. Latency decrease of the jaw reflex indicates dis inhibition of the reflex arc at brainstem level as a consequence of cortical dysfunction, as may be expected in patients with Huntington's chorea.

The blink reflex has been studied in lesions of the fifth nerve, the trigeminal complex and the lower brainstem. ${ }^{10}$ Esteban et $a l^{4}$ reported prolonged homolateral second component latencies on right, left, or both sides in eight patients with Huntington's chorea. Our patients as a group showed homo- as well as heterolateral increased second component latencies upon stimulation on either side.

A possible influence of medication ${ }^{14}$ appeared not to be of importance in our study since three out of the four patients with the most prolonged second component latencies were not on any medication.

Cortical lesions have been reported to prolong the latency of the blink reflex second component. However, the corneal reflex appears to be more sensitive to cortical lesions than the blink reflex ${ }^{811}$ and in our patients the corneal reflex latency did not differ significantly from control values, although it tended to be increased. Therefore, blink reflex abnormalities 
in our patients possibly are not to be explained by assuming impairment of descending excitatory pathways although the latter kind of impairment may have caused some corneal reflex delay.

What may be the pathophysiological meaning of the blink reflex latency increase? Preponderance of descending inhibitory pathways as a consequence of increased dopaminergic striatal influence has been proposed to account for the habituation increase of the second component of the blink reflex in Huntington's chorea. ${ }^{312}$ Preponderance of descending inhibitory pathways may very well be the explanation for the latency increase of the blink reflex second component in our patients, since a descending inhibitory preponderance does not affect the corneal reflex which is known never to habituate. ${ }^{13}$ Of course the latency increase of the blink reflex second component may also be caused by medullary and pontine reticular formation abnormalities, differentially affecting the blink reflex and the corneal reflex tracts, but these are thought to run closely together. ${ }^{10} \mathrm{~A}$ discrepancy between corneal reflex and blink reflex latency has not been reported in Huntington's chorea before and possibly points to a striatal cause for these abnormalities.

\section{References}

${ }^{1}$ Bruyn GW, Bots GThAM, Dom R. Huntington's Chorea. Current neuropathological status. In: Chase T, Wexler N, Barbeau A, eds. Advances in Neurology. New York: Raven Press, Vol. 23; 1979:83-93.

${ }^{2}$ Leigh R, Newman S, Folstein S, Lasker A, Jensen B. Abnormal oculomotor control in Huntington's disease. Neurology (NY) 1983;33:1268-75.

${ }^{3}$ Caraceni T. Study of the excitability cycle of the blink reflex in Huntington's Chorea. Eur Neurol 1976; 14:465-72.
${ }^{4}$ Esteban A, Gimenez-Roldan S. The blink reflex in Huntington's chorea and Parkinson's disease. Acta Neurol Scand 1975;52:1145-57.

${ }^{5}$ Ehle A, Stewart R, Lellelid N, Leventhal M. Evoked potentials in Huntington's disease. Arch Neurol 1984;41:379-82.

${ }^{6}$ Ongerboer de Visser BW, Goor C. Jaw reflexes and masseter electro-myograms in mesencephalic and pontine lesions. An electro-diagnostic study. J Neurol Neurosurg Psychiatry 1976;39:90-2.

${ }^{7}$ Ongerboer de Visser BW, Goor C. The cutaneous silent period in masseter muscles. A clinical and electrodiagnostic evaluation. J Neurol Neurosurg Psychiatry 1976;39:674-9.

${ }^{8}$ Ongerboer de Visser BW. Comparative study of corneal and blink reflex latencies in patients with segmental or with cerebral lesions. In: Desmedt JE, ed. Motor Control Mechanisms in Health and Disease. New York: Raven Press, 1983:727.

${ }^{9}$ Jewett DL, Williston JS. Auditory evoked far-fields averaged from the scalp of humans. Brain 1971;94:681-96.

${ }^{10}$ Ongerboer de Visser BW. Anatomical and functional organisation of reflexes involving the trigeminal system in man: jaw reflex, blink reflex, corneal reflex and exteroceptive suppression. In: Desmedt JE, ed. Motor Control Mechanisms in Health and Disease. New York: Raven Press, 1983:727-38.

${ }^{11}$ Berardelli A. Orbicularis oculi response after hemispheral damage. J Neurol Neurosurg Psychiatry 1983; 46:837-43.

${ }^{12}$ Ferguson IT, Lenman JA, Johnston BB. Habituation of the orbicularis oculi reflex in dementia and dyskinetic States. J Neurol Neurosurg Psychiatry 1978;41:824-8.

${ }^{13}$ Gregoric M. Habituation of the blink reflex. In: Desmedt JE, ed. New Developments in Electromyography and Clinical Neurophysiology Vol. 3, Basel: Karger, 1973:673-7.

${ }^{14}$ Kimura J. The blink reflex as a test for brainstem and higher central nervous system function. In: Desmedt $\mathrm{JE}$, ed. New Developments in Electromyography and Clinical Neurophysiology Vol. 3, Basel: Karger, 1973:682-91. 